\title{
Genes for super-intelligence?
}

\author{
JEFFREY A SOFAER* AND ALAN E H EMERY $\dagger$ \\ From * the Department of Oral Medicine and Oral Pathology, University of Edinburgh, \\ Old Surgeons Hall, High School Yards, Edinburgh EHI INR; and \\ $\dagger$ the University Department of Human Genetics, Western General Hospital, Edinburgh EH4 $2 \mathrm{XU}$
}

SUMMARY The results of a postal questionnaire distributed to British members of Mensa failed to confirm an association of superior intelligence with torsion dystonia, retinoblastoma, or phenylketonuria, but were consistent with real associations between high IQ and infantile autism, gout, $\dot{\infty}$ and myopia. Further confirmation of these findings in other populations might well indicate that $\sigma^{\circ}$ genes producing these disorders have more or less direct effects on cerebral development and function.

It is well known that a number of single genes can influence IQ scores, several inherited malformations and biochemical defects being associated with abnormally low levels of intelligence. Perhaps less well known are recent reports suggesting that among the families of those with certain heritable disorders there is a greater proportion of subjects with unusually high intelligence than could reasonably be expected to occur by chance. ${ }^{1}$

Six disorders for which an association with high IQ has been suggested are recessive torsion dystonia, ${ }^{2}$ retinoblastoma, ${ }^{34}$ phenylketonuria, ${ }^{56}$ infantile autism, ${ }^{7}$ gout, ${ }^{8}$ and myopia, ${ }^{9}$ though for retinoblastoma $^{10}$ and phenylketonuria 1112 there have been observations inconsistent with the earlier findings. In the present study, an attempt was made to confirm the association between each of the six disorders and unusually high intelligence. This was done not by measuring IQ in families containing affected subjects, as in the past, but by ascertaining the prevalence of the disorders in a sample of highly intelligent subjects and their first degree relatives, and, where possible, by comparing the observed prevalence with published figures for the general population. Because the biochemical basis for some of the disorders is known, and because the biochemistry of all of them may ultimately be understood, such confirmation could help to provide situations in which specific biochemical differences are known to be associated with measurable degrees of enhancement of intellectual ability. This could be a valuable step towards a better understanding of cerebral development and function.

Received for publication 10 December 1980

\section{Subjects and methods}

The subjects of the investigation were the approximately 2100 British members of Mensa, the international society for the highly intelligent Membership of Mensa is only open to people whose IQ score is at least 2 SD above the mean, approx mately within the top $2 \%$ of the general populatiof On the Cattell scale (mean 100, SD 24), which is used by Mensa as their criterion for membership, this means that eligibility is restricted to those who score 148 IQ points or more.

Each subject was sent a questionnaire designed to ascertain whether a Mensa member or any first degree relative suffered from any of the six disorders being studied. For torsion dystonia, retinoblastoma, phenylketonuria, and infantile autism a brief description of each disorder was given. Positive responses for these four conditions were noted before the data were analysed and letters sent to the subjects concerned requesting permission to confirm the diagnosis with the hospitals where they or their relatives had been seen. The criterion for myopia was the need to wear glasses for shortsightedness before the age of 10 .

\section{Results}

Of the 2100 questionnaires distributed, a total of 1355 were returned more or less fully completed, a response rate of $65 \%$. Male respondents totalled 817 , females 373 , and for the remaining 165 the sex could not be determined because insufficient $\stackrel{\mathcal{\Phi}}{\rightarrow}$ personal information had been given. The 1355 Mensa members provided information for 5821 
first degree relatives: 2647 parents, 1969 sibs, and 1205 children.

There were five positive responses for torsion dystonia, one in a Mensa member and four in relatives. Correspondence revealed that none of these was a case of true torsion dystonia. There were two positive responses for retinoblastoma, both in Mensa members, but for neither was the diagnosis confirmed. The single positive response for phenylketonuria, in the son of a Mensa member, was confirmed by a consultant psychiatrist. The population incidence per 10000 of recessive torsion dystonia, retinoblastoma, and phenylketonuria can be taken respectively as less than $0 \cdot 3,{ }^{13} 0 \cdot 3$ to $1 \cdot 0,{ }^{14}$ and $0 \cdot 6$ to $2 \cdot 0 .{ }^{15}$ The results therefore provide no evidence for abnormally high incidence of these disorders among Mensa members or their relatives, although, because of the rarity of the disorders, the sample size may have been inadequate in this respect.

TABLE 1 No of confirmed cases of infantile autism compared with reported population incidence ${ }^{17}$

\begin{tabular}{llll}
\hline & \multicolumn{3}{l}{ Autism in sibs and children of respondents } \\
\cline { 2 - 4 } $\begin{array}{l}\text { Population incidence } \\
\text { per } 10000\end{array}$ & Observed & $\begin{array}{l}\text { Per } \\
10000\end{array}$ & $\begin{array}{l}\text { Relative to general } \\
\text { population }\end{array}$ \\
\hline 2.4 & $4 / 3174$ & $12 \cdot 6$ & $3 \cdot 2-6 \cdot 3$ \\
\hline
\end{tabular}

For infantile autism there were ten positive responses, three for Mensa members themselves and seven for their relatives. In only four of these cases, all either sibs or children of respondents, was the diagnosis confirmed by a consultant psychiatrist. Assuming that it is unlikely for a case of infantile autism to become either a parent ${ }^{16}$ or a member of Mensa, the incidence of the disorder should be calculated only with respect to sibs and children of respondents. Table 1 shows that this was $3 \cdot 2$ to $6 \cdot 3$ times greater than reported for the general population.

The results for gout are compared with figures for the general population in table 2 . The prevalence among male respondents was higher than among brothers of all respondents, and data for both sexes combined show that the prevalence among sibs at mean age 35 was twice that reported for the general population at mean age 44 .

The results for myopia are summarised in table 3 . Both male and female respondents showed a significantly higher incidence of the disorder than either like-sexed sibs or children of all respondents. The incidence was similar in both sexes and comparable in sibs and children. The lower incidence among parents could perhaps be attributed to less efficient diagnosis of myopia in the parental generation.

TABLE 2 No of male, female, and all respondents, and like-sexed relatives of all respondents, for whom a positive response for gout was given. Figures for the general population ${ }^{18}$ are included for comparison

\begin{tabular}{|c|c|c|c|c|c|c|c|c|c|}
\hline & \multicolumn{9}{|c|}{ Positive responses for gout } \\
\hline & \multicolumn{3}{|l|}{ Males } & \multicolumn{3}{|c|}{ Females } & \multicolumn{3}{|c|}{ Both sexes } \\
\hline & $\begin{array}{l}\text { Mean } \\
\text { age }\end{array}$ & No & $\%$ & $\begin{array}{l}\text { Mean } \\
\text { age }\end{array}$ & No & $\%$ & $\begin{array}{l}\text { Mean } \\
\text { age }\end{array}$ & No & $\%$ \\
\hline Respondents & 36 & $14 / 817^{*}$ & $1 \cdot 7$ & 36 & $5 / 373 \dagger$ & $1 \cdot 3$ & 36 & $24 / 1355 \ddagger$ & $1 \cdot 8$ \\
\hline Sibs & 34 & $6 / 965$ & 0.6 & 35 & $5 / 918$ & 0.5 & 35 & $11 / 1969$ & 0.6 \\
\hline Children & 14 & $0 / 612$ & 0.0 & 14 & $1 / 533$ & 0.2 & 14 & $1 / 1205$ & $0 \cdot 1$ \\
\hline Parents & 64 & $50 / 1319$ & $3 \cdot 8$ & 63 & $10 / 1328$ & 0.8 & 63 & $60 / 2647$ & $2 \cdot 3$ \\
\hline \multirow[t]{2}{*}{ General population } & 二 & - & - & 一 & - & - & 44 & $13 / 5127$ & $0 \cdot 3$ \\
\hline & 58 & $65 / 2283$ & $2 \cdot 8$ & 58 & $11 / 2844$ & 0.4 & 58 & $76 / 5127$ & $1 \cdot 5$ \\
\hline
\end{tabular}

*Significantly higher than in brothers of all respondents $(p<0.05)$.

$\dagger$ Not significantly higher than in sisters of all respondents.

$\ddagger$ Not directly comparable with sibs because of unequal sex distribution.

TABLE 3 No of male, female, and all respondents, and like-sexed relatives of all respondents, who were reported to have required glasses for shortsightedness before the age of 10 . Only subjects aged 10 and above are included

\begin{tabular}{|c|c|c|c|c|c|c|}
\hline & \multicolumn{6}{|c|}{ Required glasses for shortsightedness before age 10} \\
\hline & \multicolumn{2}{|l|}{ Males } & \multicolumn{2}{|l|}{ Females } & \multicolumn{2}{|l|}{ Both sexes } \\
\hline & No & $\%$ & No & $\%$ & No & $\%$ \\
\hline Respondents & $149 / 817^{*}$ & $18 \cdot 2$ & $85 / 373^{*}$ & $22 \cdot 8$ & $270 / 1355^{*}$ & $19 \cdot 9$ \\
\hline Sibs & $101 / 932$ & $10 \cdot 8$ & $100 / 883$ & $11 \cdot 3$ & $207 / 1895$ & 10.9 \\
\hline Children & $46 / 400$ & $11 \cdot 5$ & $41 / 345$ & $11 \cdot 9$ & $91 / 788$ & $11 \cdot 5$ \\
\hline Parents & $78 / 1319$ & 5.9 & $59 / 1328$ & $4 \cdot 4$ & $137 / 2647$ & $5 \cdot 2$ \\
\hline
\end{tabular}

*Significantly higher than in either like-sexed sibs or children of all respondents $(p<0 \cdot 005)$. 
Unfortunately, it was not possible to compare these incidence figures with figures for the general population because population surveys have generally used different and more technical criteria for defining myopia.

The findings therefore appear to be consistent with real associations between high IQ and infantile autism, gout, and myopia.

\section{Discussion}

Two drawbacks of the investigation method must be borne in mind when these results are being interpreted. One concerns selection of the sample, and the other the level of ascertainment in respondents and their relatives.

The sample of respondents was a doubly selected group that consisted of only a very small proportion of all highly intelligent subjects. Firstly, the top $2 \%$ of the United Kingdom population exceeds 1 million, so that the entire British membership of Mensa (2100) represents only about $0.2 \%$ of those eligible. Secondly, only $65 \%$ of the membership responded, and the desire to co-operate may have been biased by whether or not there was something positive to report.The difficulty of sample selection is removed, however, if comparisons are made not between the sample and the general population, but within the sample between respondents and their relatives. This could be done for both gout and myopia, but the possibility of different levels of ascertainment in respondents and their relatives then becomes a potentially confounding factor.

The significantly greater prevalence of gout in male respondents than in brothers of all respondents could have been at least partly the result of a lower level of ascertainment for relatives, but since the prevalence among sibs of both sexes was rather high compared with the general population, underreporting for relatives would imply an even higher prevalence among brothers. As far as myopia is concerned, Mensa members can be expected to have responded accurately on their own children's need to wear glasses before the age of 10 . The fact that the observed incidence was similar in both sibs and children therefore suggests that under-reporting made little or no contribution to the difference between respondents and sibs for this disorder. An ascertainment effect is therefore unlikely to explain the association between high IQ and either gout or myopia in the present sample.

There are several ways in which superior intelligence and disease may be associated. An association would occur if a disorder were more readily diagnosed in brighter families. There may be a cause and effect relationship, as has been postulated for

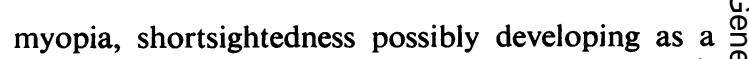
result of high IQ through reading to excess. Fortui- $\stackrel{\mathbb{P}}{=}$ tous associations could result from the chance $\overrightarrow{\vec{F}}$ occurrence of an unusually high incidence of a $\stackrel{5}{9}$ disorder in brighter families. However, because a substantial genetic component appears to be $\frac{\bar{\sigma}}{\bar{\omega}}$ involved in the aetiology of infantile autism, gout, $\frac{\bar{\sigma}}{\vec{\phi}}$ and myopia, ${ }^{19-21}$ and because IQ is also to some $\stackrel{\mathbb{Q}}{2}$ extent inherited, ${ }^{22}$ there may be purely genetic कै explanations for the observed associations. The $\overrightarrow{0}$ most attractive of these is pleiotropy, namely that the genes producing the disorders have more or less $\vec{\omega}$ direct effects on cerebral development and function. Associations for other genetic reasons such as linkage, or through chance, are unlikely to be maintained when samples from several different $\infty$ sources are studied. Therefore, assuming that appropriate allowance can be made for non- $\overrightarrow{0}$ genetic effects, the greater the variety of samples in 을 which the same association is observed, the greater the likelihood of pleiotropy.

Independent evidence for pleiotropy may be forthcoming if the biochemistry of each disorder is at least partly understood. At present this applies only to gout, in connection with which some interesting observations and speculations have been $\bar{\varnothing}$ made. Among mammals, significant levels of seruis uric acid are found only in higher apes and mar. other mammals possessing the enzyme uricas which oxidises uric acid to allantoin. It has been suggested that uric acid, like other purines, can stimulate the cerebral cortex, and that the superior intellectual powers of the higher primates may be to some extent a consequence of high uric acid levels through mutations causing loss of uricase activity. ${ }^{23}$ Consistent with this idea is the finding that glutamic acid, which is involved in the production of endogenous uric acid, ${ }^{24}$ appears to improve cognitive function when given therapeutically in cases of mental retardation..$^{25}$

It is possible that future investigations will further confirm the association between various inherited disorders and superior intelligence, and that, as the biochemistry of the disorders becomes better understood, there may be direct demonstrations of $\frac{D}{O}$ intellectual enhancement by the products of the genes involved.

The authors are grateful to the members and $N$ administration of Mensa for their co-operation; to $\underset{\omega}{N}$ Mr W Lutz, Director of Edinburgh University's $\sigma$ Medical Computing and Statistics Unit, for advice 0 on questionnaire design; and to the International $\mathbb{D}$ Brain Research Organisation, Mason Medical $\stackrel{\oplus}{+}$ Research Foundation, and W R Henderson's Trust $\square$ for financial support. 


\section{References}

1 Anonymous. Genes for superior intelligence. $\mathrm{Br} \mathrm{Med} \mathrm{J}$ 1976;i:416-7.

2 Eldridge R, Harlan A, Cooper IS, Riklan M. Superior intelligence in recessively inherited torsion dystonia. Lancet 1970 ; i:65-7.

3 Thurrell RJ, Josephson TS. Retinoblastoma and intelligence. Psychosomatics 1966;7:368-70.

4 Williams M. Superior intelligence of children blinded from retinoblastoma. Arch Dis Child 1968;43:204-10.

5 Munro TA. Phenylketonuria: data on forty-seven British families. Ann Eugen 1947;14:60-88.

6 Fuller R. Phenylketonuria: psychological and developmental evaluation. In: Anderson JA, Swaimson KF, eds. Phenylketonuria and allied metabolic diseases. Washington: US Government Printing Office, 1967:133-51.

7 Rimland B. Infantile autism. London: Methuen, 1965.

8 Anonymous. Uric acid and the psyche. JAMA 1969;208: 1180.

9 Karlsson JL. Influence of the myopia gene on brain development. Clin Genet 1975;8:314-8.

10 Eldridge R, O'Meara K, Kitchin D. Superior intelligence in sighted retinoblastoma patients and their families. $J$ Med Genet 1972;9:331-5.

11 Thalhammer O, Havelec L, Knoll E, Wehle E. Intellectual level (IQ) in heterozygotes for phenylketonuria (PKU). Hum Genet 1977;38:285-8.

12 Ford RC, Berman JL. Phenylalanine metabolism and intellectual functioning among carriers of phenylketonuria and hyperphenylalaninaemia. Lancet 1977;i:767-71.

13 Eldridge R, Edgar A, Cooper IS. Genetics, geography and intelligence in the torsion dystonias. Birth Defects 1971; VII : $167-77$.
14 Vogel F. Genetics of retinoblastoma. Hum Genet 1979; $52: 1-54$.

15 Tourain AY, Sidbury JB. Phenylketonuria. In: Stanbury JB, Wyngaarden JB, Fredrickson DS, eds. The metabolic basis of inherited disease. 4th ed. New York: McGrawHill, 1978:240-55.

16 Rutter M. Autistic children: infancy to adulthood. Semin Psychiatry 1970;2:435-50.

17 Wing L, Yeates SR, Brierly LM, Gould J. The prevalence of early childhood autism: comparison of administrative and epidemiological studies. Psychol Med 1976;6:89-100.

18 Hall AP, Barry PE, Dawber TR, McNamara M. Epidemiology of gout and hyperuricemia: a long term population study. Am J Med 1967;42:27-37.

19 Folstein S, Rutter M. Genetic influences and infantile autism. Nature 1977;265:726-8.

20 Morton NE. Genetics of hyperuricemia in families with gout. Am J Med Genet 1979;4:103-6.

21 Karlsson JL. Evidence for recessive inheritance in myopia. Clin Genet 1975;7:197-202.

22 Block N, Dworkin G. The IQ controversy. London: Quartet Books, 1977.

23 Orowan E. The origin of man. Nature 1955;175:683-4.

24 Gutman AB, Yu TF. Uric acid metabolism in normal man and in primary gout. $N$ Engl J Med 1965;273, 252-60.

25 Vogel W, Brovermen DM, Draguns JG, Klaiber EL. The role of glutamic acid in cognitive behaviours. Psychol Bull 1966;65:367-82.

Requests for reprints to Dr J A Sofaer, Department of Oral Medicine and Oral Pathology, University of Edinburgh, Old Surgeons Hall, High School Yards, Edinburgh EH1 1NR. 